\title{
Enhancing Algal Biomass, Lipid and Astaxanthin Production by Mix-Cultivation of Haematococcus Pluvialis With Simplicillium Lanosoniveum DT06
}

\section{Ran Yan}

Hebei University of Technology

\section{Xiang-Ying Xing}

Hebei University of Technology

Qing-Lin Dong ( $\sim$ qldong@hebut.edu.cn )

Hebei University of Technology https://orcid.org/0000-0001-9539-5460

Xian-Yong Yu

Hebei University of Technology

Kang-Li Shi

Hebei University of Technology

\section{Research Article}

Keywords: Mix-cultivation, Haematococcus pluvialis, Simplicillium lanosoniveum DT06, Biomass, Lipid, Astaxanthin

Posted Date: February 10th, 2021

DOI: https://doi.org/10.21203/rs.3.rs-180975/v1

License: (9) (1) This work is licensed under a Creative Commons Attribution 4.0 International License. Read Full License 
Enhancing algal biomass, lipid and astaxanthin production by mix-cultivation of Haematococcus pluvialis with Simplicillium lanosoniveum DT06

\author{
Ran Yan $^{1} \cdot$ Xiang-Ying Xing ${ }^{2} \bullet$ Qing-Lin Dong ${ }^{1} \cdot$ Xian-Yong Yu $^{1} \bullet$ Kang-Li Shi $^{1}$ \\ ${ }^{1}$ Department of Biochemical Engineering, College of Chemical Engineering, Hebei \\ University of Technology, Tianjin 300130, China \\ ${ }^{2}$ Department of Applied Chemistry, College of Chemical Engineering, Hebei \\ University of Technology, Tianjin 300130, China
}

\title{
Corresponding author:
}

Qing-Lin Dong

E-mail: qldong@hebut.edu.cn 


\section{Abstract}

To enhance algal lipid and astaxanthin synthesis, the astaxanthin-producing green alga Haematococcus pluvialis was mix-cultivated with the antibiotic-synthesizing fungus Simplicillium lanosoniveum DT06 under non-aseptic conditions (NM) in this study. Results showed that in contrast to aseptic pure culture $(\mathrm{AH})$ and non-aseptic pure culture (NH) of $H$. pluvialis, the production of cell (biomass), lipids and astaxanthin increased $56 \%$ and $119 \%, 112.4 \%$ and $279 \%, 74 \%$ and $175 \%$, reaching $2.45 \mathrm{~g} / 1,0.837$ $\mathrm{g} / 1$ and $88.84 \mathrm{mg} / 1$ respectively; the average growth rate and the average specific growth rate increased $60.8 \%$ and $133.1 \%, 19 \%$ and $31.6 \%$, reaching $194.2 \mathrm{mg} \mathrm{l}^{-1} \mathrm{~d}^{-1}$ and $0.25 \mathrm{~d}^{-1}$ respectively; and the average lipid synthesis rate and average specific lipid synthesis rate increased $112.5 \%$ and $278.66 \%, 36.15 \%$ and $97 \%$, reaching 69.75 $\mathrm{mg}^{-1} \mathrm{~d}^{-1}$ and $28.47 \mathrm{mg} \mathrm{g}^{-1} \mathrm{~d}^{-1}$ respectively; and also the content of C16-C18 fatty acids that are suitable for biofuels production increased to $83.19 \%$. Therefore, NM provides an efficient and economical way for the production of biofuels.

Keywords Mix-cultivation · Haematococcus pluvialis $\cdot$ Simplicillium lanosoniveum DT06 $\cdot$ Biomass $\cdot$ Lipid $\cdot$ Astaxanthin

\section{Introduction}

Microalgae are an important source of lipids and other molecules that can be used as feedstocks to produce biofuels and high-value products $(1,2)$. Nevertheless, algae-based biofuels (biodiesel) are now still economically unviable owing to its low productivity and high production cost $(1,3,4)$. To deal with these problems two strategies have been applied: (1) mix-cultivation of microalgae with bacteria or fungi 
to promote algal growth and lipid synthesis by taking advantage of their synergistic effects (complementary nutritional metabolisms) (5-9) and (2) co-production of high-value products along with biofuels so as to increase income and in turn reduce production costs (10-12).

Haematococcus pluvialis is a unicellular green alga, capable of synthesizing high-value astaxanthin along with lipids (13), and thus a suitable candidate for biofuel production (14-16). Whereas, H. pluvialis's low cell growth rate constrains its lipid productivity, which is attributed, at least partially, to its susceptibility to harmful bacteria and fungi that inhibit its growth severely $(9,17)$. As a matter of fact, contamination of harmful microorganisms is a major impediment to any algae for substantial production of biofuels, because aseptic cultivation of algae outdoor on an industrial scale is unachievable. Therefore, suppressing or even eliminating harmful bacteria and fungi is essential to promote cell growth and lipid synthesis of $H$. pluvialis and other algae.

In the previous studies, we isolated a symbiotic fungus simplicillium lanosoniveum DT06 from the culture broth of cyanobacterium Chroococcus sp. (18). DT06 can synthesize a new antibiotic inhibiting gram-negative bacteria and some fungi (19) and promote Chlamydomonas reinhardtii's growth and lipid production in aseptic cultures (20). Therefore, in the present study, we mix-cultivated H. pluvialis with DT06 in non-aseptic cultures to mimic the actual outdoor culture regime of $H$. pluvialis and find out if enhancements of cell, lipid and astaxanthin production can be achieved. 


\section{Materials and methods}

\subsection{Microorganisms and media}

H. pluvialis was obtained from the Institute of Hydrobiology of Chinese Academy of Science, and maintained at $4{ }^{\circ} \mathrm{C}$ in a liquid BBM medium (13). Seed culture was prepared by inoculating $5 \mathrm{ml}$ activated $H$. pluvialis culture into $250 \mathrm{ml}$ flasks containing $100 \mathrm{ml}$ of BBM medium, and incubated in an orbital shaker with top cool white fluorescent lamps at $25^{\circ} \mathrm{C}, 110 \mathrm{rpm}, 60 \mu \mathrm{mol}$ photons $\mathrm{m}^{-2} \mathrm{~s}^{-1}$.

The fungus simplicillium lanosoniveum DT06 was isolated from the culture broth of cyanobacterium Chroococcus sp. (18), which was streaked on PDA (21) agar plate and incubated at $28{ }^{\circ} \mathrm{C}$ for 7 days to facilitate spore production. The fungal spores were collected from the agar plate with $20 \mathrm{ml}$ sterile distilled water and counted using a hemacytometer under the light microscope.

\subsection{Pure and mixed-cultures}

Aseptic pure culture of $H$. Pluvialis (AH): $250 \mathrm{ml}$ flasks containing $100 \mathrm{ml}$ culture sterilized BBM medium were inoculated with $10 \%(\mathrm{v} / \mathrm{v})$ seed culture of $H$. pluvialis with a cell concentration of $2.5 \times 10^{5} / \mathrm{ml}$.

Non-aseptic pure culture of $H$. Pluvialis $(\mathrm{NH})$ were conducted in the same way as $\mathrm{AH}$, except that the BBM medium was not sterilized.

Non-aseptic mixed-culture $H$. Pluvialis and DT06 (NM): $250 \mathrm{ml}$ flasks containing $100 \mathrm{ml}$ non-sterilized BBM medium were inoculated seed culture of $H$. pluvialis $\left(2.5 \times 10^{5} / \mathrm{ml}\right)$ and DT06 spore suspension $\left(1.25 \times 10^{7} / \mathrm{ml}\right)$ to reach a cell ratio 50: 1 (H. Pluvialis: DT06). 
All cultures were incubated in an orbital shaker at $25{ }^{\circ} \mathrm{C}, 110 \mathrm{rpm}, 60 \mu \mathrm{mol}$ photons $\mathrm{m}^{-2} \mathrm{~s}^{-1}$.

\subsection{Analytical methods}

\subsubsection{Biomass and growth kinetic}

\subsubsection{Biomass}

H. pluvialis biomass (dry cell weight, DCW g 1-1) was calculated using Eq. (1) (22).

Dry cell weight $=\left[-4.2 \times\left\{\left(\mathrm{OD}_{680}-\mathrm{OD}_{750}\right) / \mathrm{OD}_{680}\right\}+1.4\right] \times \mathrm{OD}_{680}$

where, $\mathrm{OD}_{680}$ and $\mathrm{OD}_{750}$ were the absorbances of culture broths at $680 \mathrm{~nm}$ and

$750 \mathrm{~nm}$ respectively, which were measured with a Visible spectrometer $(723 \mathrm{~N}$, Shanghai, China).

\subsubsection{Growth kinetics}

The cell growth rate $\left(\mathrm{g} \mathrm{l}^{-1} \mathrm{~d}^{-1}\right)$ of $H$. pluvialis was calculated through Eq. (2).

$$
r_{g}=\frac{X_{n}-X_{0}}{t_{n}-t_{0}}
$$

The specific cell growth rate $\left(\mathrm{d}^{-1}\right)$ of $H$. pluvialis was calculated through Eq. (3).

$$
\mu=\frac{\ln \mathrm{X}_{\mathrm{n}}-\ln \mathrm{X}_{0}}{\mathrm{t}_{\mathrm{n}}-\mathrm{t}_{0}}
$$

where $X_{0}$ and $X_{n}$ is the biomass $\left(\mathrm{g} \mathrm{l}^{-1}\right)$ at day $t_{0}$ and $t_{n}$ respectively.

\subsubsection{Lipid production and synthesis kinetic}

\subsubsection{Lipid production}

$0.05 \mathrm{~g}$ of dried algal cells was blended with $5 \mathrm{ml}$ of chloroform/methanol (2: 1) and the mixture was stirred at $2000 \mathrm{rpm}$ on a magnetic stirrer for $20 \mathrm{~min}$. The procedure was carried out 2 times. All the chloroform layers were collected, combined and evaporated to dryness at $60{ }^{\circ} \mathrm{C}$. The total lipid $\left(\mathrm{G}_{\mathrm{L}}\right)$ was weighed on an analytical 
balance.

\subsubsection{Lipid synthesis kinetics}

The total lipid content $\left(\mathrm{mg} \mathrm{g}^{-1}\right)$ of H. pluvialis was calculated through Eq. (4).

$$
G\left(\mathrm{mg} \mathrm{g}^{-1}\right)=\frac{G_{L}}{V X}
$$

where $\mathrm{G}_{\mathrm{L}}$ is the total lipid (mg), $\mathrm{V}$ is the culture volume (1), $\mathrm{X}$ is biomass $\left(\mathrm{g} \mathrm{l}^{-1}\right)$.

The lipid synthesis rate: $\mathrm{r}_{\mathrm{s}}\left(\mathrm{mg} \mathrm{l}^{-1} \mathrm{~d}^{-1}\right)$ of $H$. pluvialis was calculated through Eq.

(5).

$$
r_{s}\left(m g ~^{-1} d^{-1}\right)=\frac{X_{n} G_{n}-X_{0} G_{0}}{t_{n}-t_{0}}
$$

The specific lipid synthesis rate of $H$. pluvialis was calculated through Eq. (6).

$$
\mathrm{q}\left(\mathrm{d}^{-1}\right)=\frac{\mathrm{r}_{\mathrm{s}}}{\mathrm{X}_{\mathrm{n}}}
$$

where $\mathrm{X}_{0}$ and $\mathrm{X}_{\mathrm{n}}$ is the biomass $\left(\mathrm{g} \mathrm{l}^{-1}\right)$ at day $t_{0}$ and $t_{\mathrm{n}}$, while $\mathrm{G}_{0}$ and $\mathrm{G}_{\mathrm{n}}$ is the corresponding lipid content $\left(\mathrm{mg} \mathrm{g}^{-1}\right)$ at day $\mathrm{t}_{0}$ and $\mathrm{t}_{\mathrm{n}}$, respectively.

\subsubsection{Fatty acid composition}

Fatty acid methyl ester (FAME) was prepared by extraction-transesterification (23). The extracted lipid from $0.05 \mathrm{~g}$ of dried cells was blended with $6 \mathrm{ml}$ mixture of methanol, concentrated sulfuric acid and chloroform (2.55: 0.45: 3) and kept in a water bath at $90{ }^{\circ} \mathrm{C}$ for $90 \mathrm{~min}$. Upon completion of the reaction, the chloroform layer containing FAME was carefully collected. Algal fatty acid composition was analyzed using a gas chromatograph (GC-Agilent 7890B) equipped with a flame-ionized detector (FID) and an INNOWAX capillary column (Agilent, USA; $30 \mathrm{~m} \times 0.32 \mathrm{~mm}$ $\times 0.5 \mu \mathrm{m})$. The initial column temperature was set at $80{ }^{\circ} \mathrm{C}$ for $2 \mathrm{~min}$, raised to $140{ }^{\circ} \mathrm{C}$ $\left(12{ }^{\circ} \mathrm{C} \mathrm{min}-1\right)$, then $240{ }^{\circ} \mathrm{C}\left(20^{\circ} \mathrm{C} \mathrm{min}^{-1}\right)$ and held for $20 \mathrm{~min}$. The temperatures of the 
injector and detector were $250^{\circ} \mathrm{C}$ and $280{ }^{\circ} \mathrm{C}$, respectively. FAME in the sample was identified and quantified by comparing the peak area with the standards (FAME Mix C8-C22 standard, 18920-1AMP; Sigma-Aldrich, St. Louis, MO, USA) using C17:0 as the internal standard.

\subsubsection{Astaxanthin production}

Astaxanthin was analyzed according to the method (13).

\subsubsection{Nitrate nitrogen}

Nitrate nitrogen was analyzed according to the method (24).

\subsection{6 pH}

$\mathrm{pH}$ was measured using a $\mathrm{pH}$ meter.

\section{Results}

\subsection{Cell growth}

\subsubsection{Biomass}

The growth of H. pluvialis was promoted in NM but inhibited in $\mathrm{NH}$ in comparison with AH. As shown in Fig. 1, the biomass of AH increased slowly on the first 2 days (lag phase) and rapidly from then on till the 8th day and hereafter remained relative stable at $1.57 \mathrm{~g} / \mathrm{l}$ (stationary phase). The biomass of $\mathrm{NH}$ changed in a manner similar to that of $\mathrm{AH}$ but was lower than those of $\mathrm{AH}$ and reached $1.12 \mathrm{~g} / \mathrm{l}$ at the end of experiment, which was $29 \%$ lower than that of $\mathrm{AH}$. By contrast, the biomass of NM elevated drastically from day 2 till day 10 and reached the highest value of $2.45 \mathrm{~g} / 1$ on day12, which increased $56 \%$ and $119 \%$ compared to those of $\mathrm{AH}$ and $\mathrm{NH}$, respectively. 


\subsubsection{Growth kinetic}

As shown in Table 1, the average growth rate $\left(194.2 \mathrm{mg}^{-1} \mathrm{~d}^{-1}\right)$ and average specific growth rate $\left(0.25 \mathrm{~d}^{-1}\right)$ of $H$. pluvialis in NM were the highest in three cultures, which were $60.8 \%$ and $19 \%, 133.1 \%$ and $31.6 \%$ higher than those of $\mathrm{AH}\left(120.8 \mathrm{mg} \mathrm{l}^{-1} \mathrm{~d}^{-1}\right.$, $\left.0.21 \mathrm{~d}^{-1}\right)$ and $\mathrm{NH}\left(83.3 \mathrm{mg}^{-1}, 0.19 \mathrm{~d}^{-1}\right)$, respectively.

\subsection{Lipid synthesis}

\subsubsection{Lipid concentration and lipid content}

As shown in Fig. 2, the highest lipid concentration $(0.837 \mathrm{~g} / \mathrm{l})$ and lipid content $(341.8$ $\mathrm{mg} / \mathrm{g}$ ) were achieved in NM, which increased $112.4 \%$ and $36 \%, 279 \%$ and $73 \%$ in comparison with those of AH $(0.394 \mathrm{~g} / 1,251.4 \mathrm{mg} / \mathrm{g})$ and $\mathrm{NH}(0.221 \mathrm{~g} / 1,197.5 \mathrm{mg} / \mathrm{g})$, respectively.

\subsubsection{Lipid synthesis kinetics}

The results of kinetic analyses were listed in Table 2 . The average lipid synthesis rate (69.75 $\left.\mathrm{mg} \mathrm{l}^{-1} \mathrm{~d}^{-1}\right)$ and average specific lipid synthesis rate $\left(28.47 \mathrm{mg} \mathrm{g}^{-1} \mathrm{~d}^{-1}\right)$ of $\mathrm{NM}$ were the highest among the three cultures, which were $112.5 \%$ and $36.15 \%$ higher than those of $\mathrm{AH}\left(32.83 \mathrm{mg} \mathrm{l}^{-1} \mathrm{~d}^{-1}, 20.91 \mathrm{mg} \mathrm{g}^{-1} \mathrm{~d}^{-1}\right)$ and $278.66 \%$ and $97 \%$ higher than those of $\mathrm{NH}\left(18.42 \mathrm{mg} \mathrm{l}^{-1} \mathrm{~d}^{-1}, 14.45 \mathrm{mg} \mathrm{g}^{-1} \mathrm{~d}^{-1}\right)$, respectively.

\subsection{Astaxanthin production / Astaxanthin content}

The astaxanthin production (concentration) and astaxanthin content in three cultures

(Fig. 3) were consistent with the lipid production and content (Table 2), which were highest in NM (88.84 mg/l, $36.26 \mathrm{mg} / \mathrm{g})$ followed AH $(51.04 \mathrm{mg} / \mathrm{l}, 32.51 \mathrm{mg} / \mathrm{g})$ and $\mathrm{NH}(32.31 \mathrm{mg} / 1,28.85 \mathrm{mg} / \mathrm{g})$, and thus the astaxanthin production and astaxanthin 
content of NM were $74 \%, 11.53 \%$ and $175 \%, 25.68 \%$ higher than those of $\mathrm{AH}$ and $\mathrm{NH}$, respectively.

\subsection{Fatty-acid composition}

As results shown in Table 3, the fatty acids profiles of the total lipids of $H$. pluvialis in all cultures were in the range of $\mathrm{C} 14-\mathrm{C} 22$ and mainly $\mathrm{C} 16-\mathrm{C} 18$ that are suitable for biodiesel production (25). The content of C16-C18 fatty acids of NM (83.19\%) was higher than those of $\mathrm{AH}(82.6 \%)$ and $\mathrm{NH}(80.71 \%)$, and more importantly oleic acid (C18:1), a key indicator of biodiesel quality (26), accounts for $21.69 \%$ of the total fatty acids of NM, which was $8.72 \%$ and $23.3 \%$ higher than those of $\mathrm{AH}(19.95 \%)$ and $\mathrm{NH}(17.59 \%)$, respectively. In addition, the percentage of saturated fatty acid (SFA) of NM (36.12\%) increased $4.3 \%$ and $7.5 \%$ in comparison with those of $\mathrm{AH}$ $(34.62 \%)$ and $\mathrm{NH}(33.59 \%)$, respectively.

\subsection{Nitrate nitrogen}

Variation of nitrate nitrogen concentration of three cultures (Fig. 4) followed a similar pattern. The nitrate nitrogen concentration of $\mathrm{AH}$ and $\mathrm{NH}$ declined drastically within the first 2 days, from $250 \mathrm{mg} / 1$ to $73.43 \mathrm{mg} / 1$ and $106.43 \mathrm{mg} / \mathrm{l}$, and then slowly to $11.34 \mathrm{mg} / \mathrm{l}$ and $18.53 \mathrm{mg} / \mathrm{l}$ respectively at the end of the experiment. By contrast, the nitrate nitrogen concentration of NM decreased more drastically than those of $\mathrm{AH}$ and $\mathrm{NH}$ to $40.56 \mathrm{mg} / \mathrm{l}$ on the 2 th day, and became undetectable on the 8 th day.

\section{$3.6 \mathrm{pH}$}

As shown in Fig. 5, the $\mathrm{pH}$ of $\mathrm{AH}$ and $\mathrm{NH}$ elevated quickly and continuously with the onset of experiment and reached 9.67 and 9.98 respectively at the end of the 
experiment. By contrast, the $\mathrm{pH}$ of NM increased slowly to 8.52 after 8 days, and then remained relatively constant in the range of 8.48 to 8.57 .

\section{Discussion}

The results of this study demonstrated that the production of cell (biomass) (Fig. 1), lipid (Fig. 2) and astaxanthin (Fig. 3) of H. pluvialis elevated in NM in comparison with those of $\mathrm{AH}$ and $\mathrm{NH}$.

(1) The elevation of $H$. pluvialis biomass in NM was caused definitely by the enhancement of cell growth as evidenced by the elevation of the average cell growth rate and specific growth rate (Table 1), which, in turn, might be attributed to the following factors:

(a) DT06 suppressed or even eliminated the harmful microorganisms (bacteria and fungi) by synthesizing antibiotic. Since NM and NH were both non-aseptic cultures, the decrease of biomass in $\mathrm{NH}$ compared to that of $\mathrm{AH}$ (aseptic culture) indicted the existence and inhibition of harmful microorganisms against $H$. pluvialis; while, on the other hand, the fact that the biomass of NM was higher than that of $\mathrm{AH}$ implied the suppression or even elimination of the harmful microorganisms in NM.

(b) The synergistic effects between DT06 and H. pluvialis in metabolism (complementary nutritional metabolisms). The growth of $H$. pluvialis in photoautotrophic condition depended solely on photosynthesis taking up $\mathrm{CO}_{2}$ but releasing $\mathrm{O}_{2}$, and thus were limited by both the insufficiency of former and accumulation of latter; while, on the contrary, DT06 metabolically absorbed $\mathrm{O}_{2}$ but liberated $\mathrm{CO}_{2}$, and thus promoted the growth $H$. pluvialis in NM, a case similar to 
those in other alga-microorganism co-cultures $(13,27,28,29,30)$.

(c) The metabolism of DT06 stabilized the pH of NM. The quickly elevated pHs in $\mathrm{AH}$ and $\mathrm{NH}$ (Fig. 5) inhibited cell growth, which were resulted primarily from the uptake of physiologically alkaline salts e.g., $\mathrm{NaNO}_{3}$ (Fig. 4) and secretion of $\mathrm{NH}_{4}{ }^{+}(31)$ by $H$. pluvialis; while in NM, the release of $\mathrm{CO}_{2}$ and uptake of $\mathrm{NH}_{4}^{+}$by DT06 lowered and relatively stabilized the culture pH (Fig. 5), which was in favor of $H$. pluvialis growth. Additionally, it is noteworthy that after the uptake of $\mathrm{NH}_{4}^{+}$, DT06 probably secreted organic nitrogen for the growth of $H$. pluvialis, which could explain the reason for the growth of $H$. pluvialis after day8 (Fig. 1) when nitrate nitrogen was depleted (Fig. 4).

(2) The elevation of lipid production in NM was ascribed to (a) the elevated biomass of H. pluvialis (Fig. 1) that set the cell base for enhanced synthesis of lipid, and (b) the enhancement of lipid synthesis as evidenced by the elevation of lipid content (Fig. 2), average lipid synthesis rate and specific lipid synthesis rate of $H$. pluvialis (Table 2). The reasons for this seemed to come from two aspects: firstly, the quickly depletion of nitrate nitrogen (Fig. 4), which resulted in nitrogen starvation that promoted lipid synthesis by directing the carbon flux toward the specific pathway (32), and secondly $\mathrm{CO}_{2}$ generated by DT06 increased $\mathrm{CO}_{2}$ concentration, which not only facilitated lipid synthesis (33-35) but also influenced the composition of fatty acid (36-38), and thus might be the cause for the enrichment of C16-C18 fatty acids, particularly oleic acid in NM (Table 3) as well.

(3) The reasons for the elevated astaxanthin production in NM (Fig. 3) were similar to 
or even the same as those for the enhanced lipid yield (Fig. 2). Since astaxanthin is lipid-soluble dispersing in lipid droplets in $H$. pluvialis cells $(15,16,39)$, it is not surprising that lipid and astaxanthin syntheses are closely associated, and conditions favor lipid synthesis also enhance astaxanthin production (40-42).

\section{Conclusion}

Mix-cultivation of the antibiotic-synthesizing fungus simplicillium lanosoniveum DT06 with the astaxanthin-producing green alga Haematococcus pluvialis in non-aseptic condition promotes algal growth as well as lipid and astaxanthin syntheses, and thus provides an efficient way for co-production of biofuels and high-value products.

\section{Acknowledgements}

The study was supported by the Natural Science Foundation of Hebei Province, China 200 (Grant No. D2020202004).

\section{Compliance with Ethical Standards}

\section{Conflict of Interest}

The authors declare that they have no conflict of interest.

\section{Declarations}

\section{Funding}

The study was supported by the Natural Science Foundation of Hebei Province, China 200 (Grant No. D2020202004).

\section{Conflict of Interest}

The authors declare that they have no conflict of interest. 
Availability of data and material

Not applicable

Code availability

Not applicable

Ethics approval

Not applicable

Consent to participate

Not applicable

\section{Consent for publication}

Not applicable 


\section{Authors' contributions}

Xiang-Ying Xing and Qing-Lin Dong conceived and designed this study. Ran Yan, performed the experiments and analyzed the data along with Xian-Yong Yu and Kang-Li Shi. Ran Yan and Qing-Lin Dong wrote the manuscript. 


\section{References}

1. Moreno-Garcia, L., Adjallé, K., Barnabé, S., \& Raghavan, G. S. V. (2017). Microalgae biomass production for a biorefinery system: recent advances and the way towards sustainability. Renewable and Sustainable Energy Reviews, 76, 493-506.

2. Benavente-Valdés, J. R., Aguilar, C., Contreras-Esquivel, J. C., Méndez-Zavala, A., \& Montañez, J. (2016). Strategies to enhance the production of photosynthetic pigments and lipids in chlorophycae species. Biotechnology Reports, 10, 117-125.

3. Shuba, E. S., \& Kifle, D. (2018). Microalgae to biofuels: 'Promising' alternative and renewable energy, review. Renewable and Sustainable Energy Reviews, 81, 743-755.

4. Liu, J. (2016). Interspecific biodiversity enhances biomass and lipid productivity of microalgae as biofuel feedstock. Journal of applied phycology, 28(1), 25-33.

5. Xie, S., Sun, S., Dai, S. Y., \& Yuan, J. S. (2013). Efficient coagulation of microalgae in cultures with filamentous fungi. Algal Research, 2(1), 28-33.

6. Santos, C. A., \& Reis, A. (2014). Microalgal symbiosis in biotechnology. Applied microbiology and biotechnology, 98(13), 5839-5846.

7. Lutzu, G. A., \& Turgut, D. N. (2018). Interactions of microalgae and other microorganisms for enhanced production of high-value compounds. Front Biosci, $23,1487-1504$.

8. Hu, Z., Qi, Y., Zhao, L., \& Chen, G. (2019). Interactions between microalgae and microorganisms for wastewater remediation and biofuel production. Waste and 
Biomass Valorization, 10(12), 3907-3919.

9. Padmaperuma, G., Kapoore, R. V., Gilmour, D. J., \& Vaidyanathan, S. (2018). Microbial consortia: a critical look at microalgae co-cultures for enhanced biomanufacturing. Critical reviews in biotechnology, 38(5), 690-703.

10. Barsanti, L., \& Gualtieri, P. (2018). Is exploitation of microalgae economically and energetically sustainable?. Algal research, 31, 107-115.

11. Rösch, C., Roßmann, M., \& Weickert, S. (2019). Microalgae for integrated food and fuel production. Gcb Bioenergy, 11(1), 326-334.

12. Zhu, L. (2015). Biorefinery as a promising approach to promote microalgae industry: An innovative framework. Renewable and sustainable energy reviews, $41,1376-1384$.

13. Dong, Q. L., \& Zhao, X. M. (2004). In situ carbon dioxide fixation in the process of natural astaxanthin production by a mixed culture of Haematococcus pluvialis and Phaffia rhodozyma. Catalysis Today, 98(4), 537-544.

14. Cerón, M. C., García-Malea, M. D. C., Rivas, J., Acien, F. G., Fernández, J. M., Del Río, E., Guerrero, M. G., \& Molina, E. (2007). Antioxidant activity of Haematococcus pluvialis cells grown in continuous culture as a function of their carotenoid and fatty acid content. Applied microbiology and biotechnology, 74(5), 1112.

15. Damiani, M. C., Popovich, C. A., Constenla, D., \& Leonardi, P. I. (2010). Lipid analysis in Haematococcus pluvialis to assess its potential use as a biodiesel feedstock. Bioresource technology, 101(11), 3801-3807. 
16. Saha, S. K., McHugh, E., Hayes, J., Moane, S., Walsh, D., \& Murray, P. (2013). Effect of various stress-regulatory factors on biomass and lipid production in microalga Haematococcus pluvialis. Bioresource technology, 128, 118-124.

17. Molina, D., de Carvalho, J. C., Júnior, A. I. M., Faulds, C., Bertrand, E., \& Soccol, C. R. (2019). Biological contamination and its chemical control in microalgal mass cultures. Applied microbiology and biotechnology, 103(23-24), 9345-9358.

18. Dong, Q. L., Lin, T. Y., Xing, X. Y., Chen, B., \& Han, Y. (2014). Identification of a symbiotic fungus from blue-green alga and its extracellular polysaccharide. Letters in applied microbiology, 58(4), 303-310.

19. Dong, Q., Dong, R., Xing, X., \& Li, Y. (2018). A new antibiotic produced by the cyanobacterium-symbiotic fungus Simplicillium lanosoniveum. Natural product research, 32(11), 1348-1352.

20. Dong, Q. L., Wang, Y. Q., Xing, X. Y., Gao, H. J., \& Li, T. T. (2018). Enhancing cell growth and lipid production of Chlamydomonas reinhardtii by co-culturing with the fungus Simplicillium lanosoniveum. Microbiology China, 45(12), 2637-2647.

21. Dong, Q., Wang, H., Xing, X., \& Ji, S. (2012). Identification and characterization of a special species of Paecilomyces. Annals of microbiology, 62(4), 1587-1592.

22. Lababpour, A., Shimahara, K., Hada, K., Kyoui, Y., Katsuda, T., \& Katoh, S. (2005). Fed-batch culture under illumination with blue light emitting diodes (LEDs) for astaxanthin production by Haematococcus pluvialis. Journal of bioscience and bioengineering, 100(3), 339-342. 
23. Indarti, E., Majid, M. I. A., Hashim, R., \& Chong, A. (2005). Direct FAME synthesis for rapid total lipid analysis from fish oil and cod liver oil. Journal of Food Composition and Analysis, 18(2-3), 161-170.

24. Hecht, U., \& Mohr, H. (1990). Factors controlling nitrate and ammonium accumulation in mustard (Sinapis alba) seedlings. Physiologia plantarum, 78(3), $379-387$.

25. Cheirsilp, B., \& Torpee, S. (2012). Enhanced growth and lipid production of microalgae under mixotrophic culture condition: effect of light intensity, glucose concentration and fed-batch cultivation. Bioresource technology, 110, 510-516.

26. Ho, S. H., Chen, W. M., \& Chang, J. S. (2010). Scenedesmus obliquus CNW-N as a potential candidate for $\mathrm{CO} 2$ mitigation and biodiesel production. Bioresource technology, 101(22), 8725-8730.

27. Imase, M., Watanabe, K., Aoyagi, H., \& Tanaka, H. (2008). Construction of an artificial symbiotic community using a Chlorella-symbiont association as a model. FEMS microbiology ecology, 63(3), 273-282.

28. Cheirsilp, B., Suwannarat, W., \& Niyomdecha, R. (2011). Mixed culture of oleaginous yeast Rhodotorula glutinis and microalga Chlorella vulgaris for lipid production from industrial wastes and its use as biodiesel feedstock. New Biotechnology, 28(4), 362-368.

29. Shu, C. H., Tsai, C. C., Liao, W. H., Chen, K. Y., \& Huang, H. C. (2012). Effects of light quality on the accumulation of oil in a mixed culture of Chlorella sp. and Saccharomyces cerevisiae. Journal of Chemical Technology \& Biotechnology, 
$87(5), 601-607$.

30. Sahin, D., Altindag, U. H., \& Tas, E. (2018). Enhancement of docosahexaenoic acid (DHA) and beta-carotene production in Schizochytrium sp. using symbiotic relationship with Rhodotorula glutinis. Process Biochemistry, 75, 10-15.

31. Dong, Q. L., Zhao, X. M., Xing, X. Y., Hu, J. Z., \& Gong, J. X. (2007). Concomitant $\mathrm{NH}+4$ secretion during astaxanthin synthesis in Haematococcus pluvialis under high irradiance and nitrogen deficient conditions. Chinese Journal of Chemical Engineering, 15(2), 162-166.

32. Dong, Q. L., Zhao, X. M., Ma, H. W., Xing, X. Y., \& Sun, N. X. (2006). Metabolic flux analysis of the two astaxanthin-producing microorganisms Haematococcus pluvialis and Phaffia rhodozyma in the pure and mixed cultures. Biotechnology Journal: Healthcare Nutrition Technology, 1(11), 1283-1292.

33. Moghimifam, R., Niknam, V., Ebrahimzadeh, H., \& Hejazi, M. A. (2020). CO2 biofixation and fatty acid composition of two indigenous Dunaliella sp. isolates (ABRIINW-CH2 and ABRIINW-SH33) in response to extremely high CO2 levels. Bioprocess and Biosystems Engineering, 43(9), 1587-1597.

34. Hosseini, N. S., Shang, H., \& Scott, J. A. (2018). Biosequestration of industrial off-gas $\mathrm{CO} 2$ for enhanced lipid productivity in open microalgae cultivation systems. Renewable and Sustainable Energy Reviews, 92, 458-469.

35. Higgins, B. T., Labavitch, J. M., \& VanderGheynst, J. S. (2015). Co-culturing Chlorella minutissima with Escherichia coli can increase neutral lipid production and improve biodiesel quality. Biotechnology and Bioengineering, 112(9), 
1801-1809.

36. Wu, S., Huang, A., Zhang, B., Huan, L., Zhao, P., Lin, A., \& Wang, G. (2015). Enzyme activity highlights the importance of the oxidative pentose phosphate pathway in lipid accumulation and growth of Phaeodactylum tricornutum under CO2 concentration. Biotechnology for biofuels, 8(1), 1-11.

37. Sun, Z., Dou, X., Wu, J., He, B., Wang, Y., \& Chen, Y. F. (2016). Enhanced lipid accumulation of photoautotrophic microalgae by high-dose $\mathrm{CO} 2$ mimics a heterotrophic characterization. World Journal of Microbiology and Biotechnology, $32(1), 9$.

38. Wang, X. W., Liang, J. R., Luo, C. S., Chen, C. P., \& Gao, Y. H. (2014). Biomass, total lipid production, and fatty acid composition of the marine diatom Chaetoceros muelleri in response to different $\mathrm{CO} 2$ levels. Bioresource technology, $161,124-130$.

39. Wayama, M., Ota, S., Matsuura, H., Nango, N., Hirata, A., \& Kawano, S. (2013). Three-dimensional ultrastructural study of oil and astaxanthin accumulation during encystment in the green alga Haematococcus pluvialis. PloS one, 8(1), e53618.

40. Cifuentes, A. S., Gonzalez, M. A., Vargas, S., Hoeneisen, M., \& Gonzalez, N. (2003). Optimization of biomass, total carotenoids and astaxanthin production in Haematococcus pluvialis Flotow strain Steptoe (Nevada, USA) under laboratory conditions. Biological Research, 36(3-4), 343-357.

41. Cerón, M. C., García-Malea, M. D. C., Rivas, J., Acien, F. G., Fernández, J. M., 
Del Río, E., Guerrero, M. G., \& Molina, E. (2007). Antioxidant activity of Haematococcus pluvialis cells grown in continuous culture as a function of their carotenoid and fatty acid content. Applied microbiology and biotechnology, 74(5), 1112.

42. Pang, N., Gu, X., Fu, X., \& Chen, S. (2019). Effects of gluconate on biomass improvement and light stress tolerance of Haematococcus pluvialis in mixotrophic culture. Algal Research, 43, 101647. 


\section{Figure Captions}

Fig. 1 The growth curve of $H$. pluvialis

Fig. 2 Lipid concentrations and lipid contents of different cultures

Fig. 3 The astaxanthin production and astaxanthin content in different cultures

Fig. 4 Variation of nitrate nitrogen concentration in different cultures

Fig. 5 Fluctuation of $\mathrm{pH}$ in different cultures 
Table 1 The growth kinetic parameters of $H$. pluvialis of different cultures

\begin{tabular}{lll}
\hline Different & Average growth rates $/\left(\mathrm{mg} \mathrm{l}^{-1} \mathrm{~d}^{-1}\right)$ & Average specific growth \\
cultures & rate $/\left(\mathrm{d}^{-1}\right)$ \\
\hline $\mathrm{AH}$ & $120.8 \pm 3.13$ & $0.21 \pm 0.02$ \\
$\mathrm{NH}$ & $83.3 \pm 2.28$ & $0.19 \pm 0.03$ \\
$\mathrm{NM}$ & $194.2 \pm 4.12$ & $0.25 \pm 0.01$ \\
\hline
\end{tabular}


Table 2 The lipid synthesis kinetic parameters of different cultures

\begin{tabular}{lll}
\hline Different & Average lipid synthesis rate / Average specific lipid synthesis \\
cultures & $\left(\mathrm{mg} \mathrm{l}^{-1} \mathrm{~d}^{-1}\right)$ & rate $/\left(\mathrm{mg} \mathrm{g}^{-1} \mathrm{~d}^{-1}\right)$ \\
\hline $\mathrm{AH}$ & $32.83 \pm 0.12$ & $20.91 \pm 0.14$ \\
$\mathrm{NH}$ & $18.42 \pm 0.63$ & $14.45 \pm 0.21$ \\
$\mathrm{NM}$ & $69.75 \pm 0.42$ & $28.47 \pm 0.22$ \\
\hline
\end{tabular}


Table 3 The fatty acid profiles of $H$. pluvialis in different cultures

\begin{tabular}{|c|c|c|c|}
\hline Fatty acids & $\mathrm{AH}$ & $\mathrm{NH}$ & $\mathrm{NM}$ \\
\hline C14:0 & $1.32 \pm 0.15$ & $2.87 \pm 0.12$ & $2.04 \pm 0.05$ \\
\hline $\mathrm{C} 16: 0$ & $18.62 \pm 1.35$ & $15.74 \pm 1.15$ & $19.14 \pm 1.21$ \\
\hline C16:1 & $4.44 \pm 0.22$ & $5.63 \pm 0.13$ & $4.61 \pm 0.22$ \\
\hline $\mathrm{C} 16: 2$ & $3.02 \pm 0.11$ & $3.76 \pm 0.56$ & $2.93 \pm 0.08$ \\
\hline $\mathrm{C} 16: 3$ & $3.94 \pm 0.18$ & $4.11 \pm 0.84$ & $2.12 \pm 0.09$ \\
\hline C18:0 & $4.67 \pm 0.21$ & $4.62 \pm 0.35$ & $4.96 \pm 0.15$ \\
\hline C18:1 & $19.95 \pm 1.31$ & $17.59 \pm 1.36$ & $21.69 \pm 1.32$ \\
\hline C18:2 & $18.64 \pm 1.16$ & $16.47 \pm 1.33$ & $19.23 \pm 1.26$ \\
\hline C18:3 & $9.32 \pm 0.33$ & $12.79 \pm 0.98$ & $8.51 \pm 0.35$ \\
\hline C20:0 & $7.43 \pm 0.17$ & $7.93 \pm 0.47$ & $7.63 \pm 0.21$ \\
\hline C20:1 & $3.17 \pm 0.06$ & $3.7 \pm 0.31$ & $2.95 \pm 0.04$ \\
\hline $\mathrm{C} 22: 0$ & $2.58 \pm 0.13$ & $2.43 \pm 0.24$ & $2.35 \pm 0.07$ \\
\hline $\mathrm{C} 22: 1$ & $2.9 \pm 0.11$ & $2.36 \pm 0.27$ & $1.84 \pm 0.08$ \\
\hline SFA & $34.62 \pm 1.47$ & $33.59 \pm 1.62$ & $36.12 \pm 1.51$ \\
\hline C16-C18 & $82.6 \pm 2.13$ & $80.71 \pm 1.99$ & $83.19 \pm 1.78$ \\
\hline
\end{tabular}


Figures

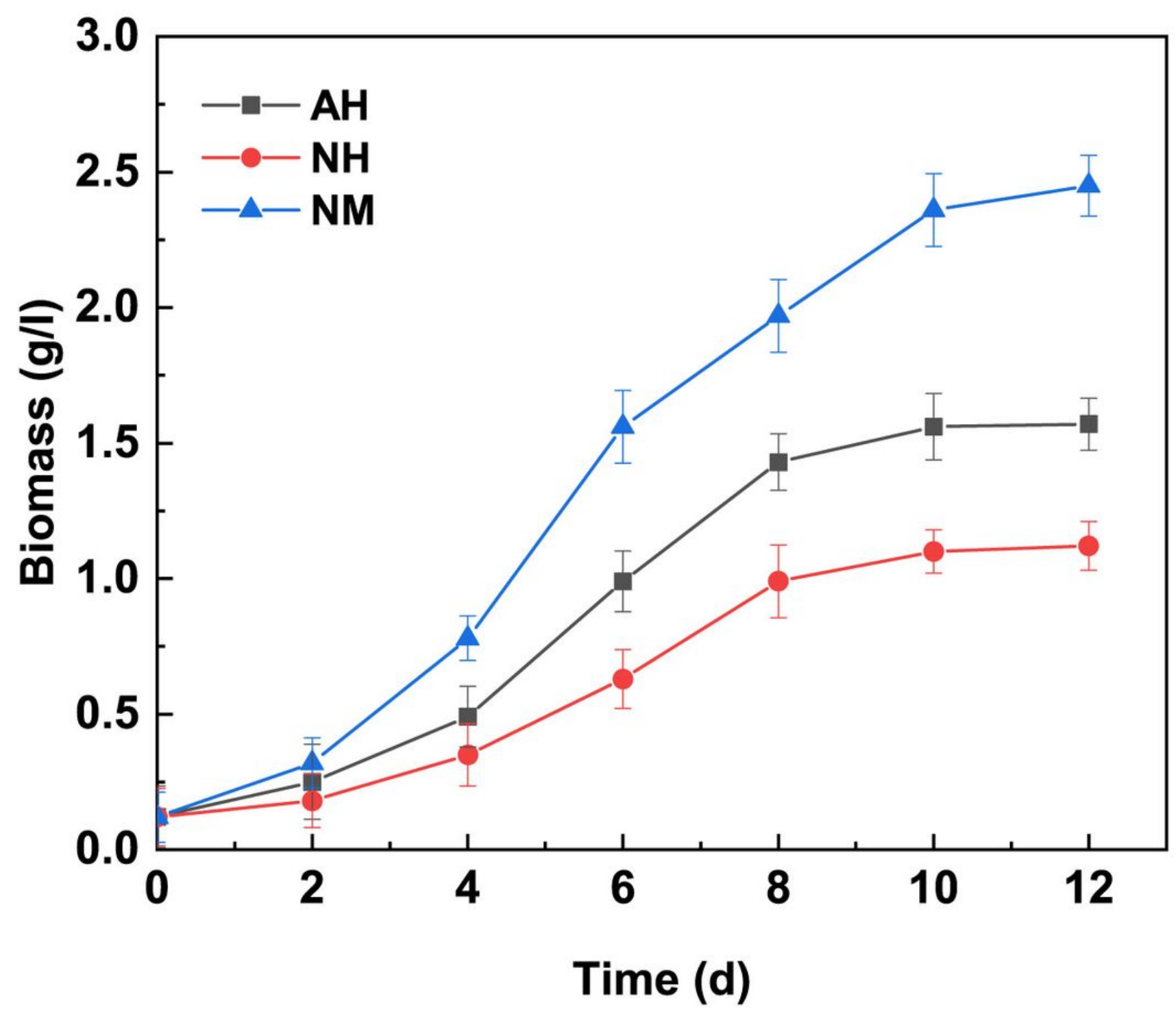

Figure 1

The growth curve of $\mathrm{H}$. pluvialis 


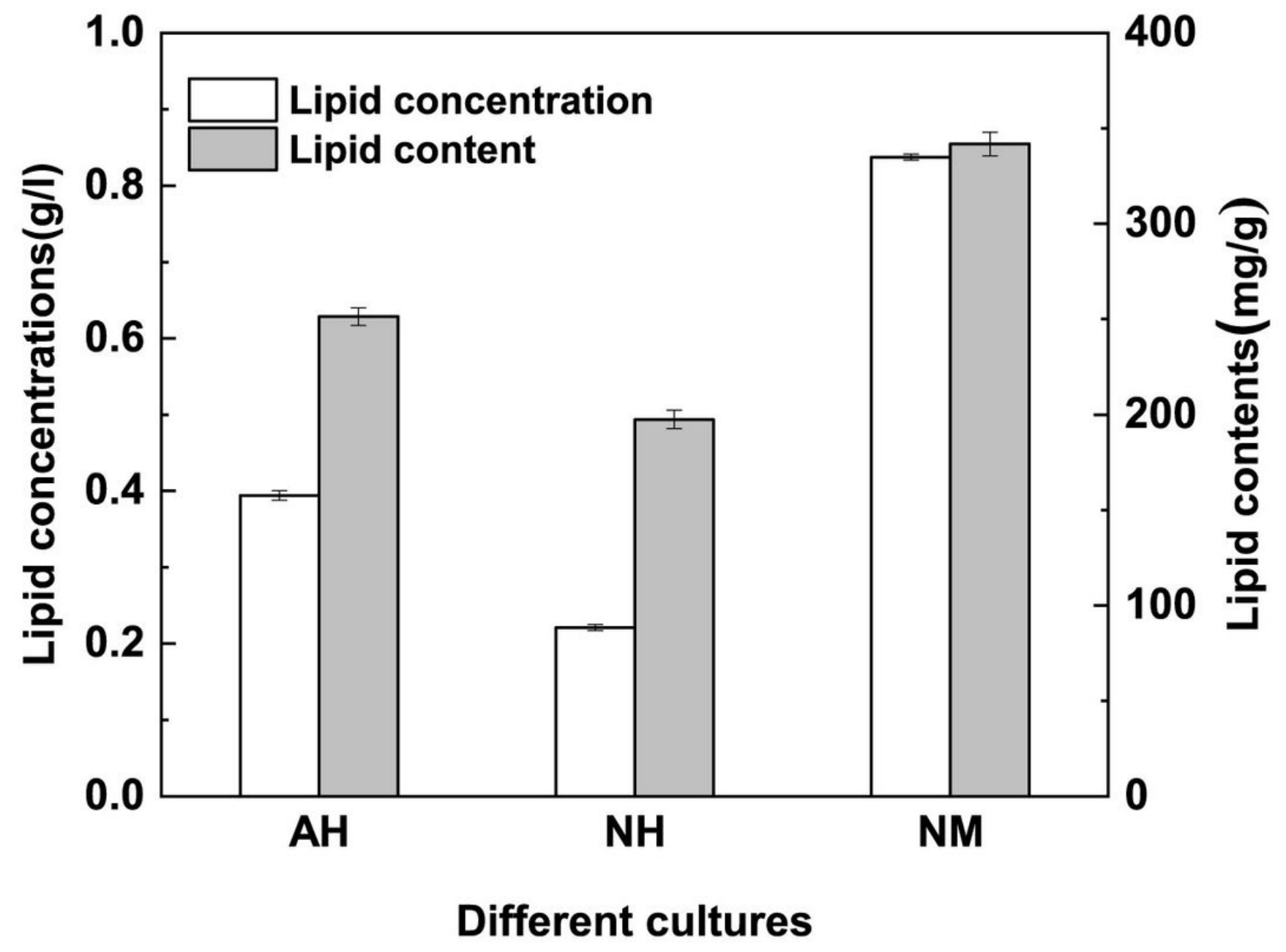

Figure 2

Lipid concentrations and lipid contents of different cultures 


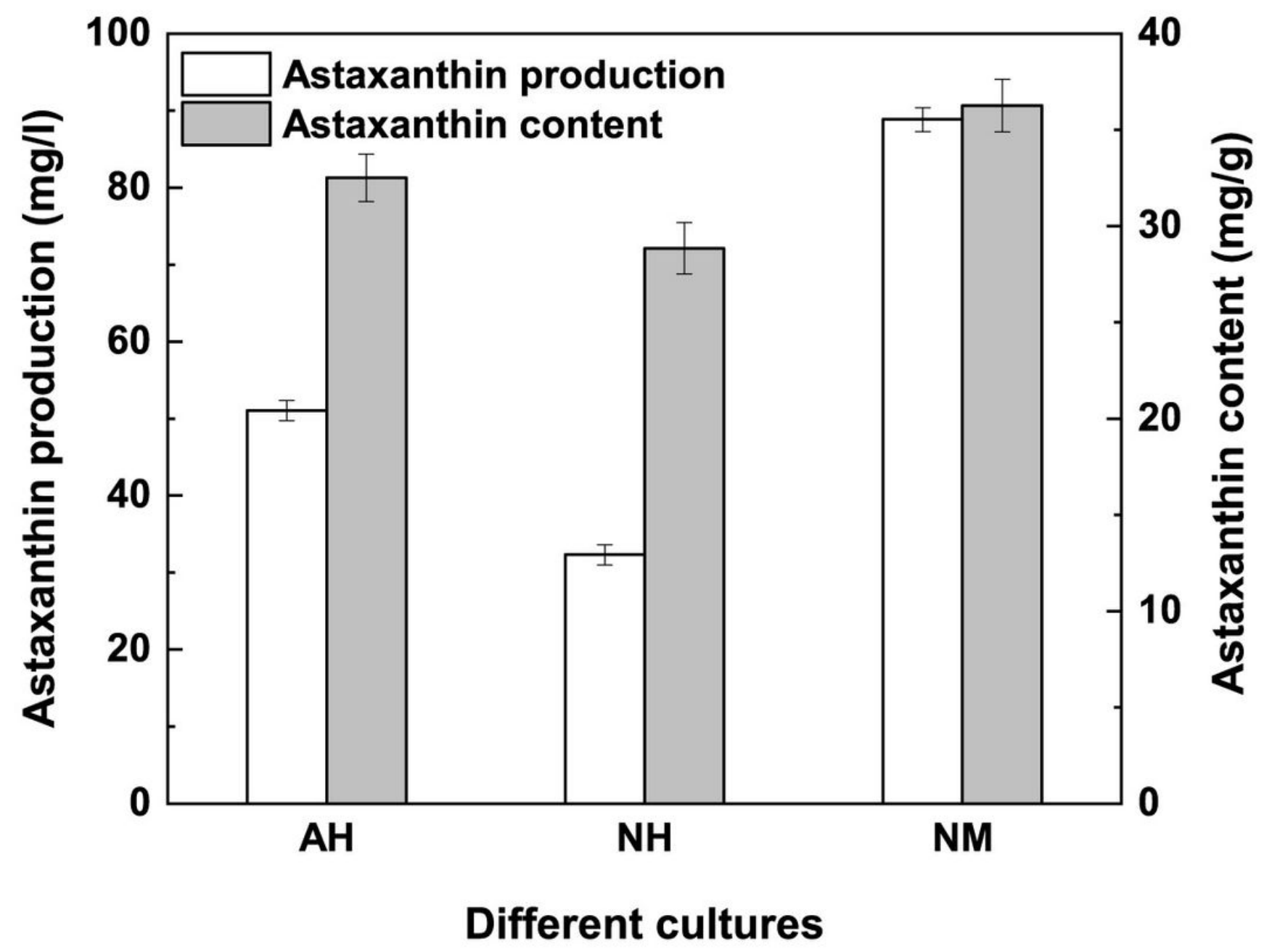

Figure 3

The astaxanthin production and astaxanthin content in different cultures 


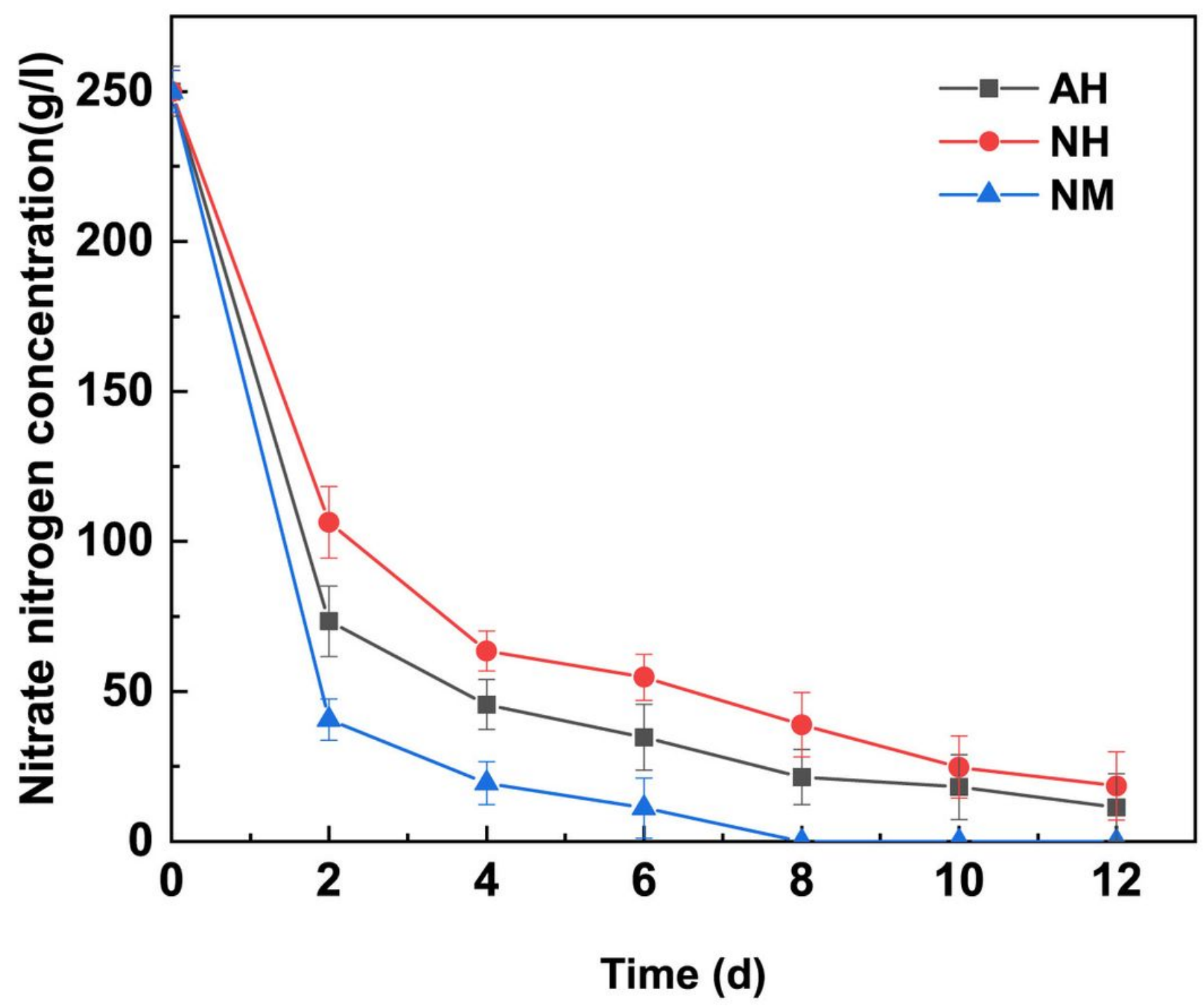

Figure 4

Variation of nitrate nitrogen concentration in different cultures 


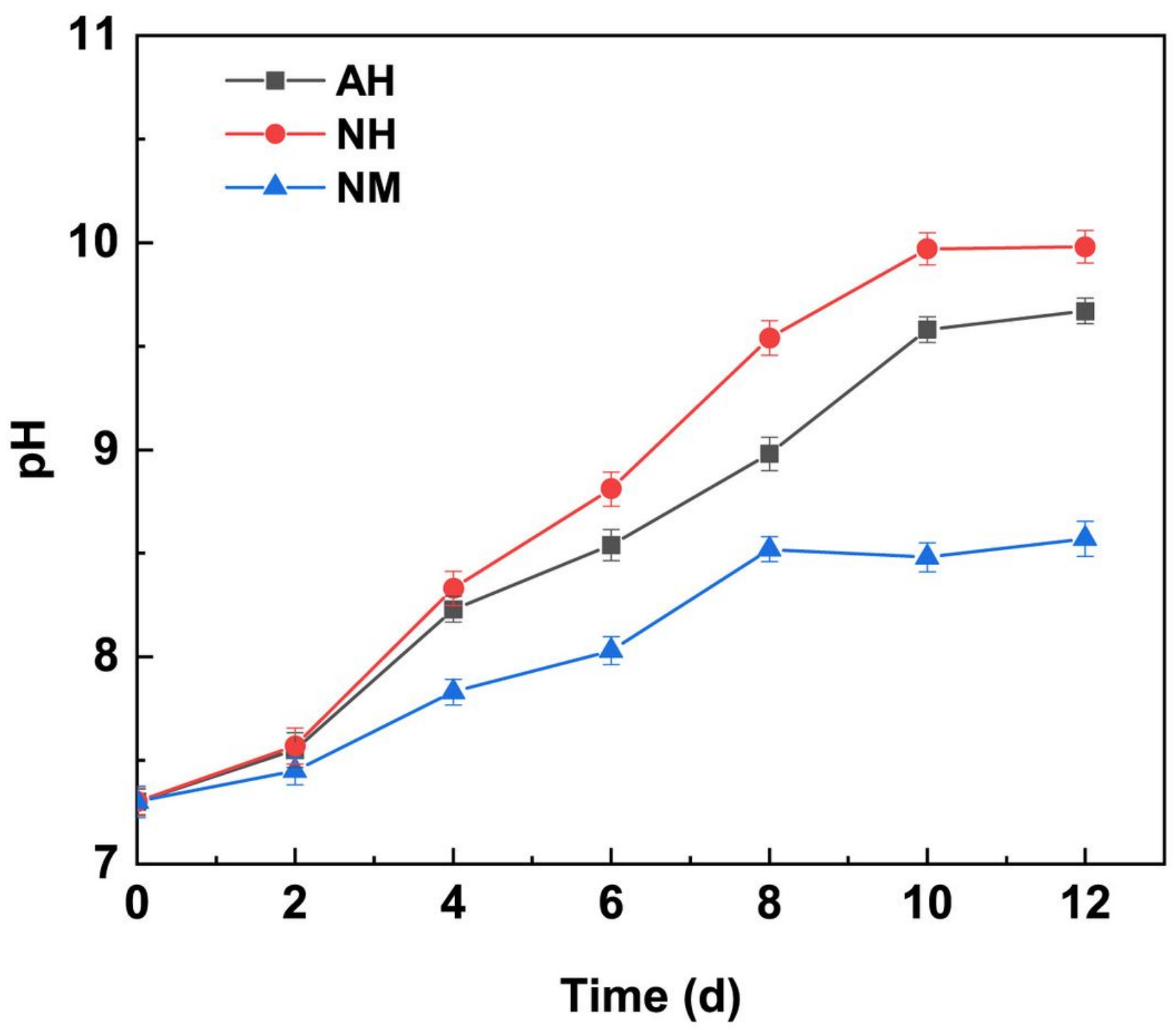

Figure 5

Fluctuation of $\mathrm{pH}$ in different cultures 